tensive subjects. It nevertheless remains possible that $\mathrm{K}$ depletion may be deleterious in other ways as yet unrecognized, or in other disease states such as heart failure, liver disease, the nephrotic syndrome, or in patients taking digitalis (Wolf and Parmley, 1964; Friedberg, 1966).

We are indebted to Dr. J. G. Devlin and Miss Margaret Moloney, of St. Laurence's Hospital, for the plasma insulin and glucose estimations.

REFERENCES

Abbrecht, P. H. (1969). Fournal of Clinical Investigation, 48, 432.

Amatuzio, D. S., Stutzman, F. L., Vanderbilt, M. J., and Nesbitt, S. (1953). Fournal of Clinical Investigation, 32, 428 .

Bartorelli, C., Gargano, N., and Leonetti, G. (1966). In Antihypertensive Therapy, edited by F.'Gross, p. 422. Berlin, Springer.

Buchan, D. J., and Houston, C. S. (1965). Canadian Medical Association fournal, $92,176$.

Clarke, E., Evans, B. M., MacIntyre, I., and Milne, M. D. (1955). Clinical Sciènce, 14, 421 .

Conn, J. W. (1955). fournal of Laboratory and Clinical Medicine, 45, 3, 661.

Conway, E. T. (1957). Microdiffusion Analysis and Volumetric Error, 4th ed., pp. 98, 201. London, Crosby Lockwood.

Cranston, W. I., et al. (1963). Lancet, 2, 966.

Dollery, C. T., Pentecost, B. L., and Samann, N. A. (1962). Lancet, 2, 735.

Earley, L. E., and Orloff, J. (1964). Annual Review of Medicine, 15, 149.
Friedberg, C. K. (1966). Diseases of the Heart, p. 401. Philadelphia, Saunders.

Gardner, L. I., Talbot, N. B., Cook, C. D., Berman, H., and Uribe, C. R. (1950). Fournal of Laboratory and Clinical Medicine, 35, 592.

Garnett, E. S., Ford, J., Golding, P. L., Mardell, R. J., and Whyman, A. E. (1968). Clinical Science, 35, 93.

Gifford, R. W., jun., Mattox, V. R., Orvis, A. L., Sones, D. A., and Rosevear, J. W. (1961). Circulation, 24, 1197.

Goldner, M. G., Zarowitz, H., and Akgun, S. (1960). New England fournal of Medicine, 262, 403 .

Hales, C. N., and Randle, P. J. (1963a). Biochemical fournal, 88, 137.

Hales, C. N., and Randle, P. J. (1963b). Lancet, 1, 200.

Kakaviatos, N., Davidov, M., Garvilovic, L., and Finnerty, F. A., jun. (1967). Lancet, 2, 725

Lawrason, F. D., Alpert, E. Mohr, F. L., and McMahon, F. G. (1965). Fournal of the American Medical Association, 191, 641.

Remenchik, A. P., and Johnston, L. C. (1966). American fournal of Medical Sciences, 252, 171.

Schwartz, W. B., and Relman, A. S. (1955). fournal of Clinical Investigation, 32, 258.

Spergel, G., Schmidt, P., Stern, A., and Bleicher, S. J. (1957). Diabetes, $16,312$.

Surawicz, B., et al. (1957). American fournal of Medical Sciences, 233, 603.

Talso, P. J., and Carballo, A. J. (1960). Annals of the New York Academy of Sciences, 88, 822 .

Veal, N., and Vetter, H. (1958). Radioisotopes Techniques in Clinical Research and Diagnosis, p. 191. London, Butterworths.

Wolf, F. W., and Parmley, W. W. (1964). Diabetes, 13, 115.

Wrong, O., and Davies, H. E. F. (1959). Quarterly fournal of Medicine, 28, 259.

\title{
Effect of Externally Applied Pressure on Femoral Vein Blood Flow
}

\author{
M. SPIRO, ${ }^{*}$ M.CHIR., F.R.C.S. ; V. C. ROBERTS, $\dagger$ B.SC.(ENG.), M.SC., A.K.c. ; J. B. RICHARDS, $†$ B.SC.(ENG.)
}

British Medical fournal, 1970, 1, 719-723

\begin{abstract}
Cummary: The effect of incremental increases in external $\checkmark$ pressure, applied to the leg, on blood volume flow in the femoral vein was studied in dogs. Clinical investigation of external pressure increases was also carried out on nine patients undergoing surgery for varicose veins. An external pressure between 5 and $15 \mathrm{~mm}$. $\mathrm{Hg}$ caused a sustained increase in mean femoral vein flow both in a control and in the compressed limb. Above 15 $\mathrm{mm}$. Hg external pressure flow decreased in the compressed limb but was maintained at an increased level in the control limb.

If external compression is to be used to prevent and treat deep vein thrombosis its application must be carefully controlled.
\end{abstract}

\section{Introduction}

Pulmonary embolus is still a major cause of postoperative morbidity and mortality (Hodgson, 1964). A large proportion of these emboli arise from thrombosis in the deep veins of the leg (McLachlin and Paterson, 1951). The aetiological factors predisposing to such thrombosis are many and still the subject of investigation. We believe that stasis is one of the important factors.

In order to minimize stasis in the leg veins two methods that have been employed either alone or in combination are the application of compression bandages to occlude the superficial veins and raising the legs above the horizontal to empty the superficial veins. That stasis occurs in patients maintained in the horizontal supine position has been elegantly demonstrated by McLachlin, McLachlin, Jory, and Rawling, 1960. These workers also showed that with a $15^{\circ}$ head-down tilt on the table stasis was largely eliminated. Venous flow velocity (Wright

*Clinical Research Assistant and Honorary Senior Surgical Registrar. †Research Assistant, Biomechanics Department, King's College Hospital Medical School, London S.E.5.

$\ddagger$ Present address: Rush Green Hospital, Romford, Essex. and Osborn, 1952) and possibly total limb blood flow were increased (Beaconsfield and Ginsberg, 1955) by this manœuvre.

Increase in the velocity of deep venous blood flow by external compression was first reported by Stanton, Freis, and Wilkins (1949) and more recently by Makin, Mayes, and Holroyd (1969). It has, however, also been shown that total limb flow may be seriously impaired by external compression (Ashton, 1966; Ginsberg, Miller, and McElfatrick, 1967; Campion, Hoffman, and Jepson, 1968). Furthermore, venous flow may be impaired and stasis increased by certain forms of external compression (Husni, Ximenes, and Hamilton, 1968).

The purpose of this paper is to report an investigation into the effect of incremental increases in external compression on blood volume flow rate in the femoral vein as distinct from flow velocities. Also included are the results of an investigation into the compression achieved by crêpe and Bisgaard bandages applied by a group of nurses.

\section{Method}

Preliminary investigations were carried out in one greyhound and detailed investigations in a further three weighing from 26 to $29 \mathrm{~kg}$. Blood flows were measured with a Nycotron blood flowmeter type 372, using Nycotron acute flow probes type PS. Careful calibration of the probes was previously performed on several dogs, the aspiration technique recommended by the manufacturers being used, and by timed collection during controlled perfusion of one of the hind limbs. Before measuring femoral vein flow the electromagnetic flowmeter was allowed to warm up for at least an hour.

Femoral vein pressures were measured in dogs by means of a Bell and Howell pressure transducer type L221, recorded on a Devices M4 recorder.

\section{Animal Experiments}

General anaesthesia was induced with intravenous pentobarbitone sodium in a dose of $30 \mathrm{mg} . / \mathrm{kg}$. and maintained with supplementary doses as required. The iliac and femoral 
veins of one hind limb were exposed and all tributaries between the deep thigh veins and the internal iliac vein ligated and divided. In one dog both iliac and femoral veins were exposed and flows measured in each while a selected range of external pressures was applied to one limb, the other limb acting as a control, as shown in Fig. 1.

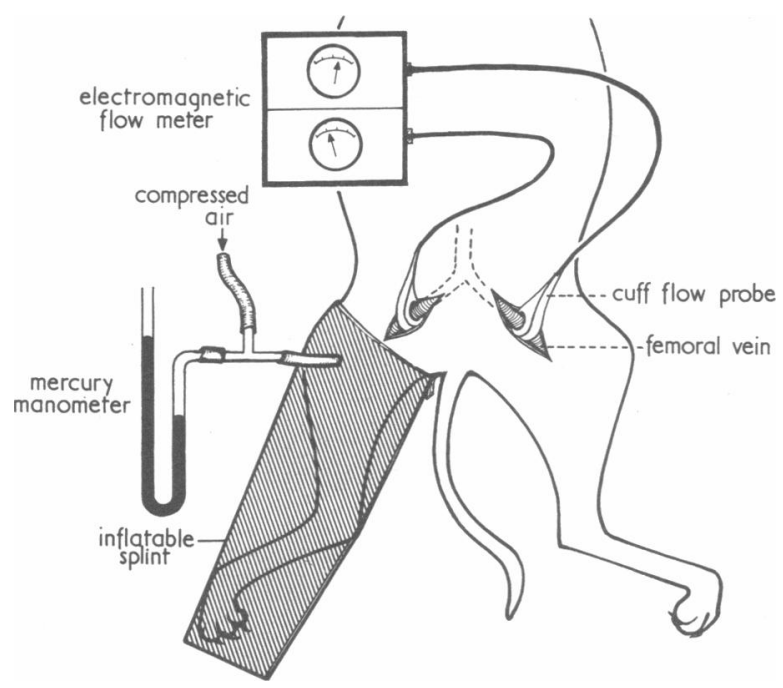

FIG. 1.-Experiment for determining effects of externally applied pressure on femoral vein blood flow in dog.

External pressure was applied to the limb with an inflatable plastic splint (Parke Davis \& Co.). Simultaneous measurements of deep femoral vein pressure were also made in the compressed limb by passing a catheter retrogradely into the main vein via a deep tributary so that the tip of the catheter lay in a section of the vein beneath the compressing splint. Continuous records of blood flow were traced by an ultra violet recorder as the splint was inflated and held at pressures varying from 0 to $140 \mathrm{~mm}$. $\mathrm{Hg}$. Each pressure was maintained for five minutes and was followed by a recovery period of five minutes. The mean blood flows were obtained from the traces by planimetry.

\section{Patient Investigation}

Nine patients undergoing surgery for bilateral varicose veins were asked for their informed consent to the procedure, which was fully explained in every case. The procedure was comparable to the animal experiments, but'certain modifications were made to avoid prolonging the operative time and to avoid any undue interference with the femoral vein. Each period of compression and each period of rest lasted only until a steady state had been achieved and maintained for one minute. This usually meant that each period lasted only two minutes instead of five minutes for the animal experiments. In two patients, however (Cases 3 and 7), the compression was sustained for four-minute periods in order to confirm that the increased flow was maintained. Pressures were not measured in the femoral vein, as to do so would have added unjustifiably to the operative procedure.

General anaesthesia was induced and maintained with spontaneous respiration, as venous flows might be grossly affected with controlled respiration (Dyde and Bethal, 1968). The patient was placed supine on a horizontal table. Both saphenofemoral junctions were exposed and flow probes fitted to the femoral vein proximal to the saphenofemoral junction. As these probes lay very close to the termination of the long saphenous vein this was occluded during the flow recording to ensure axisymmetric flow through the probe.

The left leg was used as a control. The right leg was placed in an inflatable splint (either a below-knee splint or a fulllength leg and thigh splint). Flows were measured in the femoral vein with varying splint pressures. No control was possible in one patient (Case 1), as he was only undergoing unilateral surgery, and in another (Case 4) owing to probe failure.

\section{Leg Bandaging}

In this investigation a group of 22 nurses were asked to bandage the leg below the knee with a crêpe bandage and with a Bisgaard bandage. They were not informed of the purpose of the investigation. The external pressure applied to the leg by these procedures was measured by strapping a small incompressible plastic bag to the subject's leg. The dimensions of the bag were 17.5 by 1.6 by $0.11 \mathrm{~cm}$. It contained a very small quantity of water, resulting in a thickness-to-width ratio of $1: 14 \cdot 4$. The pressure in the bag was transmitted by a manometer line to the pressure transducer and traced on the Devices recorder. Pressure measurements were made before and after bandaging had been completed with the leg placed horizontally at rest in a reference position.

\section{Verification of Recording Technique}

The assumption that the pressure recorded in the bandaging experiments was in fact transmitted to the limb was verified. The small incompressible bag was strapped to the medial aspect of the lower calf and the limb placed in an inflatable splint. Increments of pressure were then applied to the limb by inflating the splint, and the compression pressure transmitted to the bag was recorded. The results show that for splint pressures below $40 \mathrm{~mm}$. $\mathrm{Hg}$ the two systems agree within $5 \%$. At splint pressures greater than $40 \mathrm{~mm}$. Hg the compression pressure-indicating system shows a slight fall off caused by a leakage of fluid from the system.

\section{Results}

\section{Animal Experiments}

The effect of applied pressure on femoral vein flow and pressure in three dogs is shown in Table I. Percentage change

TABLE I.-Effects of Externally Applied Pressure on Femoral Vein Flow and Deep Femoral Vein Pressure in the Dog. Sustained Change in Flow $(\Delta Q \%)$ is Tabulated Against the Change in Deep Femoral Vein Pressure ( $\Delta P \mathrm{~mm} . \mathrm{Hg}$ ) for Increments of Applied Pressure from 5 to $140 \mathrm{~mm}$. $\mathrm{Hg}$

\begin{tabular}{|c|c|c|c|c|c|c|}
\hline \multirow{2}{*}{$\begin{array}{c}\text { Splint } \\
\text { Pressure } \\
(\mathrm{mm} . \mathrm{Hg})\end{array}$} & \multicolumn{2}{|c|}{$\operatorname{Dog} 1$} & \multicolumn{2}{|c|}{ Dog 2} & \multicolumn{2}{|c|}{$\operatorname{Dog} 3$} \\
\hline & $\Delta \mathrm{Q} \%$ & $\begin{array}{c}\Delta \mathrm{P} \\
\mathrm{mm} . \mathrm{Hg}\end{array}$ & $\Delta \mathbf{Q} \%$ & $\begin{array}{c}\Delta \mathrm{P} \\
\mathrm{mm} . \mathrm{Hg}\end{array}$ & $\Delta \mathrm{Q} \%$ & $\underset{\mathrm{mm} . \mathrm{Hg}}{\Delta \mathrm{P}}$ \\
\hline $\begin{array}{r}5 \\
10 \\
15 \\
20 \\
40 \\
60 \\
80 \\
100 \\
120 \\
140\end{array}$ & $\begin{array}{r}-14.5 \\
+14.5 \\
-7.6 \\
-18.9 \\
-49.0 \\
-66.0 \\
-72.8 \\
-82.0 \\
-77.5 \\
-72.7\end{array}$ & $\begin{array}{r}- \\
3 \cdot 2 \\
8 \cdot 0 \\
2 \cdot 5 \\
32 \cdot 5 \\
48 \cdot 0 \\
51 \cdot 5 \\
48 \cdot 0 \\
35 \cdot 0 \\
27 \cdot 5\end{array}$ & $\begin{array}{l}-3.4 \\
=\quad 1.5 \\
=5.3 \\
=6.8 \\
=30.4 \\
-41.2 \\
-50.7 \\
-50.5 \\
-51.8 \\
-54.7\end{array}$ & $\begin{array}{r}2 \cdot 0 \\
3.0 \\
5.5 \\
8.5 \\
23 \cdot 0 \\
37 \cdot 0 \\
53 \cdot 0 \\
70 \cdot 5 \\
79 \cdot 0 \\
88 \cdot 0\end{array}$ & $\begin{array}{l}+3.0 \\
+11.2 \\
-11.1 \\
-11.0 \\
-28.6 \\
-40.8 \\
-46.7 \\
-52.6 \\
-55.0 \\
-56.3\end{array}$ & $\begin{array}{r}1 \cdot 0 \\
9.0 \\
14.0 \\
25 \cdot 0 \\
33 \cdot 0 \\
20 \cdot 0 \\
- \\
15 \cdot 0 \\
= \\
-\end{array}$ \\
\hline
\end{tabular}

in flow $\triangle \mathrm{Q}$ is shown for increments of pressure from 5 to $140 \mathrm{~mm}$. Hg. Similarly change in deep femoral vein pressure $(\triangle \mathrm{P}$ in $\mathrm{mm} . \mathrm{Hg})$ is shown over the same range of splint pressures.

The effects of pressure applied externally to one limb of a $\mathrm{dog}$, on femoral vein flow in both limbs, are shown in Table II. The increments of pressure are restricted in this dog to between 10 and $40 \mathrm{~mm}$. $\mathrm{Hg}$. Sustained percentage change in flow in the control leg $\triangle \mathbf{C}$ is shown together with sustained percentage change in flow in the compressed limb (experimental limb) $\triangle \mathrm{E}$. The net percentage change referred to the control limb is $\triangle \mathrm{E}-\triangle \mathrm{C}$. 
TABLE II.-Effects of Externally Applied Pressure on Femoral Vein Flow in the Dog. Sustained Change in Flow in the Experimental (Compressed) Limb $\left(\Delta E_{\%} \%\right)$ is Tabulated Against Sustained Change in the Control (Uncompressed) Limb ( $\Delta C \%)$ for Splint Pressures of 10, 20, and $40 \mathrm{~mm}$. Hg. The Net Change Referred to the Control Limb is Shown as $(\Delta C-\Delta E) \%$

\begin{tabular}{|c|c|c|c|c|c|c|}
\hline & & & & \multicolumn{3}{|c|}{ Splint Pressure (mm. Hg) } \\
\hline & & & & 10 & 20 & 40 \\
\hline 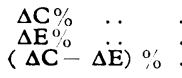 & $\begin{array}{l}\cdots \\
\cdots \\
\cdots\end{array}$ & $\begin{array}{l}\cdots \\
\cdots\end{array}$ & $\begin{array}{l}\ldots \\
\cdots \\
\cdots\end{array}$ & $\begin{array}{r}-4.5 \\
+\quad 9.3 \\
+13.8\end{array}$ & $\begin{array}{l}+1.3 \\
-5.8 \\
-7.1\end{array}$ & $\begin{array}{r}+18.7 \\
-\quad 7.7 \\
-26.4\end{array}$ \\
\hline
\end{tabular}

The results plotted from Table $I$ are given in Fig. 2. With splint pressures above $12 \mathrm{~mm}$. $\mathrm{Hg}$ the femoral vein flow shows a progressive decrease. The points which are the mean values obtained from the three sets of data in Table $I$ indicate an asymptotic reduction in flow at pressures greater than $100 \mathrm{~mm}$. $\mathrm{Hg}$ where the reduction is about $60 \%$. The maximum and

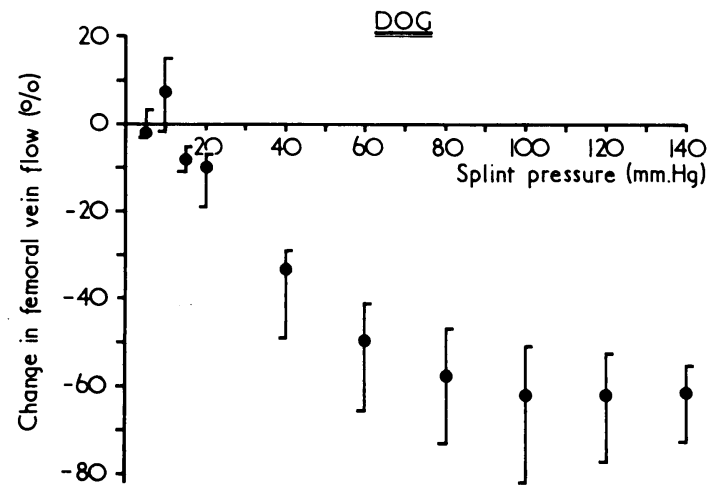

FIG. 2.-Change in femoral vein blood flow in dog as a function of externally applied pressure.

minimum flow changes are indicated by the vertical lines. The effect on deep vein pressure of -externally applied pressure indicates that while the increase produced at each increment of applied pressure follows the external pressure it does not equal it.

\section{Investigation of Patients}

The patients investigated yielded results comparable to those obtained in the animal experiments. In three patients investigations were performed with both a below-knee splint and a full-length leg and thigh splint. In three further patients only the below-knee splint was used; in another three patients only the leg and thigh splint was used. This provided six sets of data for each type of splint.

The effects of compression on femoral vein flow with the below-knee splint and with the full-length splint are shown in Tables III and IV. In both tables data are tabulated for splint pressures from 5 to $40 \mathrm{~mm}$. $\mathrm{Hg}$. The results plotted from these

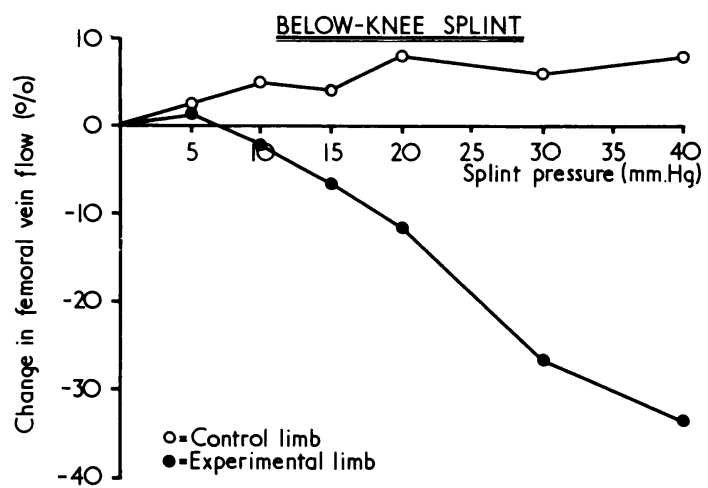

FIG. 3.-Changes in femoral vein blood flow produced by varying splint pressures for below-knee splint. tables are given in Figs. 3 and 4 respectively. The points are the mean values taken only from the patients from whom complete sets of data were obtained. The remaining patients (Cases 1 and 3 in Table III and Cases 7 and 4 in Table IV), though excluded because of incomplete data, showed a similar trend. The two curves in Fig. 3 indicate the flow changes $\triangle \mathrm{E}$ and $\triangle \mathrm{C}$ in the experimental and control limbs respectively as a function of splint pressure. The results obtained with the full-length splint are given in Fig. 4.

TABLE III.-Effects of Below-Knee Splint on Femoral Vein Flow. Sustained Change in Control Limb Flow $(\Delta C \%)$ is Tabulated Against Sustained Change in Experimental (Compressed) Limb Flow $(\Delta E \%)$ for Increments of Splint Pressure from 5 to $40 \mathrm{~mm}$. Hg. The Net Change Referred to the Control Limb is Also Given

\begin{tabular}{|c|c|c|c|c|c|c|c|}
\hline \multirow{2}{*}{$\begin{array}{l}\text { Case } \\
\text { No. }\end{array}$} & & \multicolumn{6}{|c|}{ Splint Pressure $(\mathrm{mm} . \mathrm{Hg})$} \\
\hline & & 5 & 10 & 15 & 20 & 30 & 40 \\
\hline 1\{ & $\begin{array}{r}\Delta \mathbf{C C} \% \\
\Delta \mathrm{E} \% \\
\mathrm{Net} \%\end{array}$ & $\begin{array}{l}\bar{z} \\
\bar{z}\end{array}$ & $\begin{aligned} & - \\
+ & 3.1 \\
+ & 3.1\end{aligned}$ & $\begin{array}{r}- \\
+\quad 2.9 \\
+\quad 2.9\end{array}$ & $\begin{aligned} & - \\
= & 8.4 \\
- & 8.4\end{aligned}$ & $\begin{array}{l}\bar{z} \\
\overline{-}\end{array}$ & $\begin{array}{l}-\overline{22} \cdot 3 \\
-22 \cdot 3\end{array}$ \\
\hline 2\{ & $\begin{array}{r}\Delta \mathbf{C} \% \\
\Delta \mathrm{E} \% \\
\mathbf{N e t} \%\end{array}$ & $\begin{array}{r}+4.9 \\
+10.2 \\
+\quad 5.3\end{array}$ & $\begin{array}{r}+\quad 4.9 \\
+4.0 \\
-0.9\end{array}$ & $\begin{array}{r}+7.3 \\
+\quad 9.3 \\
+\quad 2.0\end{array}$ & $\begin{array}{r}+4.9 \\
+\quad 1.0 \\
-\quad 5.9\end{array}$ & $\begin{array}{l}+3.6 \\
-11.3 \\
-14.9\end{array}$ & $\begin{array}{r}2.4 \\
+26.9 \\
-29.3\end{array}$ \\
\hline 3\{ & $\begin{array}{r}\Delta \mathbf{C} \% \\
\Delta \mathrm{E} \% \\
\text { Net \% }\end{array}$ & $\begin{array}{l}\bar{z} \\
\overline{-}\end{array}$ & $\begin{array}{r}2.3 \\
+\quad 4.8 \\
+7.1\end{array}$ & $\bar{z}$ & $\begin{array}{l}\bar{z} \\
\overline{-}\end{array}$ & $\begin{array}{l}+9.2 \\
-13.3 \\
-22.5\end{array}$ & $\begin{array}{r}+4.6 \\
+19.2 \\
-23.8\end{array}$ \\
\hline 4\{ & $\begin{array}{r}\Delta \mathrm{C} \% \\
\Delta \mathrm{E} \% \\
\mathrm{Net} \%\end{array}$ & $\begin{array}{l}0.0 \\
0.0 \\
0.0\end{array}$ & $\begin{array}{r}0.0 \\
-\quad 3.5 \\
-\quad 3.5\end{array}$ & $\begin{array}{r}0.0 \\
-9.2 \\
-9.2\end{array}$ & $\begin{array}{r}+1.3 \\
-18.9 \\
-20.2\end{array}$ & $\begin{array}{r}+8.9 \\
-32 \cdot 3 \\
-41.2\end{array}$ & $\begin{array}{l}+4 \cdot 6 \\
-36 \cdot 9 \\
-45 \cdot 1\end{array}$ \\
\hline 5\{ & $\begin{array}{r}\Delta \mathrm{C} \% \\
\Delta \mathrm{E} \% \\
\text { Net \% }\end{array}$ & $\begin{array}{l}+2.5 \\
+1.2 \\
+1.3\end{array}$ & $\begin{array}{r}0.0 \\
-\quad 6.7 \\
-\quad 6.7\end{array}$ & $\begin{array}{r}5.7 \\
+\quad 9.5 \\
-15.2\end{array}$ & $\begin{array}{l}+12.1 \\
-13.4 \\
-25.5\end{array}$ & $\begin{array}{r}8.6 \\
+25.0 \\
-33.6\end{array}$ & $\begin{array}{l}+19 \cdot 4 \\
-28 \cdot 8 \\
-48 \cdot 2\end{array}$ \\
\hline 6\{ & $\begin{array}{r}\Delta \mathbf{C} \% \\
\Delta \mathrm{E} \% \\
\mathbf{N e t} \%\end{array}$ & $\begin{array}{r}0.0 \\
-6.1 \\
-6.1\end{array}$ & $\begin{array}{r}+13.5 \\
+2.0 \\
-15.5\end{array}$ & $\begin{array}{l}+2.4 \\
-17.3 \\
-19.7\end{array}$ & $\begin{array}{r}+12.5 \\
-12.3 \\
-24.8\end{array}$ & $\begin{array}{r}+2.2 \\
-37.7 \\
-39.9\end{array}$ & $\begin{array}{r}5.0 \\
+40.9 \\
-45.9\end{array}$ \\
\hline
\end{tabular}

TABLE IV.-Effects of Full-length Leg and Thigh Splint on Femoral Vein Flow. Sustained Change in Control Limb Flow $(\Delta C \%)$ is Tabulated Against Sustained Change in Experimental (Compressed) Limb Flow $(\Delta E \%)$ for Increments of Splint Pressure from 5 to $40 \mathrm{~mm}$. Hg. The Net Change Referred to the Control Limb is Also Given

\begin{tabular}{|c|c|c|c|c|c|c|c|}
\hline \multirow{2}{*}{$\begin{array}{l}\text { Case } \\
\text { No. }\end{array}$} & & \multicolumn{6}{|c|}{ Splint Pressure (mm. $\mathbf{H g}$ ) } \\
\hline & & 5 & 10 & 15 & 20 & 30 & 40 \\
\hline 7 & $\begin{array}{r}\Delta \mathrm{C} \% \\
\Delta \mathrm{E} \% \\
\text { Net } \%\end{array}$ & $\begin{array}{r}3.8 \\
0.0 \\
+\quad 3.8\end{array}$ & $\begin{array}{r}2 \cdot 8 \\
+38 \cdot 0 \\
+40.8\end{array}$ & $\bar{z}$ & $\begin{array}{l}-3.1 \\
+\quad 3.0 \\
+\quad 6.1\end{array}$ & $\begin{array}{r}+5.2 \\
+3.6 \\
-1.6\end{array}$ & $\begin{array}{r}1.8 \\
0.0 \\
-1.8\end{array}$ \\
\hline 8 & $\begin{array}{r}\Delta \mathrm{C} \% \\
\Delta \mathrm{E} \% \\
\text { Net } \%\end{array}$ & $\begin{array}{r}+32.7 \\
+33.8 \\
+\quad 1.1\end{array}$ & $\begin{array}{r}+8.9 \\
+23.4 \\
+14.5\end{array}$ & $\begin{array}{r}+20.7 \\
+15.0 \\
-\quad 5.7\end{array}$ & $\begin{array}{r}+20.7 \\
+25.9 \\
+\quad 5.2\end{array}$ & $\begin{array}{r}+24.0 \\
+19.3 \\
-\quad 5.1\end{array}$ & $\begin{array}{l}+12.4 \\
+14.2 \\
+1.8\end{array}$ \\
\hline 4 & $\begin{array}{r}\Delta \mathrm{C} \% \\
\Delta \mathrm{E} \% \\
\text { Net } \%\end{array}$ & $\begin{array}{r}- \\
+8 \cdot 6 \\
+8.6\end{array}$ & $\begin{array}{r}- \\
=1.7 \\
-1.7\end{array}$ & $\begin{array}{l}\overline{-} \\
-\end{array}$ & $\begin{array}{l}- \\
-\end{array}$ & $\begin{array}{r}\overline{28} \cdot 6 \\
-28.6\end{array}$ & $\begin{array}{l}\bar{z} \\
\overline{-}\end{array}$ \\
\hline 2 & $\begin{array}{r}\Delta \mathrm{C} \% \\
\Delta \mathrm{E} \% \\
\text { Net } \%\end{array}$ & $\begin{array}{r}0.0 \\
+14.0 \\
+14.0\end{array}$ & $\begin{array}{l}+2.4 \\
+9 \cdot 6 \\
+7 \cdot 2\end{array}$ & $\begin{array}{r}0.0 \\
+\quad 5.0 \\
+\quad 5.0\end{array}$ & $\begin{array}{r}7.5 \\
0.0 \\
-7.5\end{array}$ & $\begin{array}{r}2.4 \\
-17.6 \\
-15.2\end{array}$ & $\begin{array}{l}+3.7 \\
-21.8 \\
-25.5\end{array}$ \\
\hline 5\{ & $\begin{array}{r}\Delta \mathrm{C} \% \\
\Delta \mathrm{E} \% \\
\text { Net \% }\end{array}$ & $\begin{array}{l}+8 \cdot 1 \\
+\quad 3.0 \\
-\quad 5.1\end{array}$ & $\begin{array}{r}+10.5 \\
-5.1 \\
-15.6\end{array}$ & $\begin{array}{l}+17.9 \\
-11.9 \\
-29.8\end{array}$ & $\begin{array}{r}+7.7 \\
-20.9 \\
-28.6\end{array}$ & $\begin{array}{l}+15.0 \\
-27.5 \\
-42.5\end{array}$ & $\begin{array}{r}+8.9 \\
-41.1 \\
-50.0\end{array}$ \\
\hline 9\{ & $\begin{array}{r}\Delta \mathrm{C} \% \\
\Delta \mathrm{E} \% \\
\text { Net } \%\end{array}$ & $\begin{array}{r}+5.5 \\
+\quad 4.9 \\
-0.6\end{array}$ & $\begin{array}{r}+19 \cdot 7 \\
0.0 \\
-19.7\end{array}$ & $\begin{array}{r}+15.0 \\
-\quad 7.3 \\
-22.3\end{array}$ & $\begin{array}{l}+9.0 \\
-12.9 \\
-21.9\end{array}$ & $\begin{array}{r}+23.2 \\
-11.8 \\
-35.0\end{array}$ & $\begin{array}{l}+19.2 \\
+30.0 \\
-49.2\end{array}$ \\
\hline
\end{tabular}

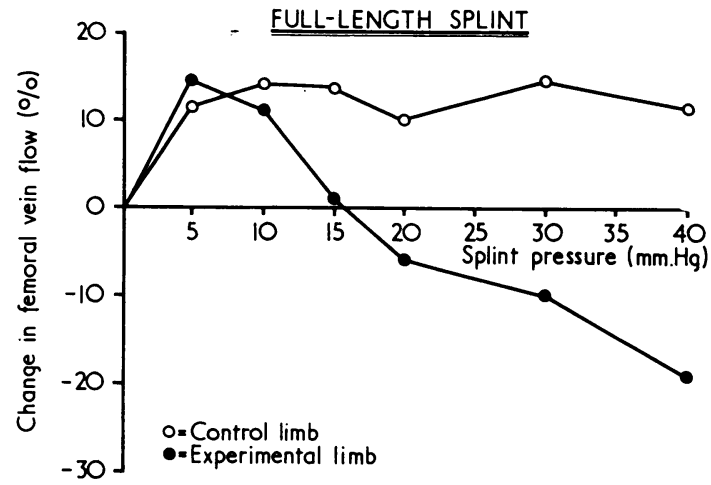

FIG. 4.- Changes in human femoral vein blood flow produced by varying splint pressures for full-length leg and thigh splint. 


\section{Leg Bandaging}

Pressures produced by crêpe bandages varied from 4 to 27 $\mathrm{mm}$. $\mathrm{Hg}$, with a mean of $13 \mathrm{~mm}$. $\mathrm{Hg}$. Compression pressures produced by the Bisgaard bandage varied from 5 to $40 \mathrm{~mm}$. $\mathrm{Hg}$, with a mean of $23.8 \mathrm{~mm}$. $\mathrm{Hg}$. The results are given in Table $\dot{V}$. The bandaging pressure is indicated in increments of

Table V.-Compression Pressures Achieved by a Group of 22 Nurses Using Crêpe and Bisgaard Bandages

\begin{tabular}{|c|c|c|c|c|c|c|c|c|c|}
\hline \multirow{2}{*}{\multicolumn{3}{|c|}{ Bandage }} & \multicolumn{7}{|c|}{ Bandaging Pressure (mm. $\mathrm{Hg})$} \\
\hline & & & $0-6$ & $6-12$ & $12-18$ & $18-24$ & $24-30$ & $30-36$ & $36-42$ \\
\hline $\begin{array}{l}\text { Crêpe... } \\
\text { Bisgaard }\end{array}$ & $\because$. & 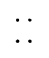 & $\begin{array}{l}1 \\
1\end{array}$ & 11 & $\begin{array}{l}6 \\
5\end{array}$ & $\begin{array}{l}3 \\
5\end{array}$ & $\begin{array}{l}1 \\
6\end{array}$ & 2 & 3 \\
\hline
\end{tabular}

$6 \mathrm{~mm}$. Hg. Eleven out of 22 nurses produced compression pressures between 6 and $12 \mathrm{~mm}$. $\mathrm{Hg}$ with the crêpe bandage. With the Bisgaard bandage a wider range of pressures resulted.

\section{Discussion}

In an attempt to control volume flow rate in the femoral vein we investigated the effect of external compression on the leg. The animal experiments, though few in number, indicated a constant increase in volume flow rate in the femoral vein at low pressures. At higher pressures a considerable decrease in flow rate was seen. The anatomy of the dog hind leg differs in two important respects from that of the human leg. The ratio of thigh muscle mass to calf muscle mass is much greater in the dog than in the human. Furthermore, the venous drainage of the dog hind limb is poorly divided into superficial and deep, whereas in man the distinction between the two systems is well demarcated. The results from the animal experiments, however, encouraged us to proceed to clinical investigation and thus to obtain data more applicable to the human condition.

The below-knee splint produced consistently increased flows in the control limb, simultaneously with a progressive decrease in experimental limb flow, as the splint pressure was increased. At $5 \mathrm{~mm}$. $\mathrm{Hg}$ there is a mean increase in flow in both limbs of about $2 \%$ (Fig. 3). Higher splint pressures result in a gradual increase in control limb flow (maximum $8 \%$ and a progressive decrease in experimental limb flow (minimum 33\%). In one patient (Case 5) a maximal increase in control limb flow of nearly $20 \%$ was achieved, while in another (Case 6) a maximal decrease in the experimental limb of $41 \%$ was achieved (Table III).

The full-length splint (Fig. 4) produced, at $5 \mathrm{~mm}$. $\mathrm{Hg}$, a flow increase in both limbs of about $13 \%$. At higher pressures the increase in control limb flow was substantially maintained while the experimental limb flow showed a progressive fall to a minimum of about $20 \%$. For pressures less than $15 \mathrm{~mm}$. $\mathrm{Hg}$ both limbs showed.an increase in flow. One patient (Case 8) achieved a maximal increase in both experimental limb flow and control limb flow of about $33 \%$ at $5 \mathrm{~mm}$. Hg external pressure, while in another patient (Case 5) a maximal decrease in experimental limb flow of $41 \%$ was achieved (Table IV).

Though we were unable to record venous pressures in our clinical investigation we did note in the animal experiments that at external compression pressures of 5 and $10 \mathrm{~mm} . \mathrm{Hg}$ (Table I) a rise in venous pressure was associated in Dogs 1 and 3 with an increase in the volume flow rate. Higher external pressures producing higher venous pressures were associated with decreased flow rates-that is, stasis.

The frequent use of compression bandaging in the treatment and prophylaxis of deep venous thrombosis prompted us to investigate the variation in pressure achieved by this technique. We were surprised at the uniformity obtained with the crêpe bandage, which was usually applied at what we would consider an optimum pressure. The results with the heavy web Bisgaard bandage, however, showed its obvious danger (Table V).

A preliminary report by Husni et al. (1968) showed that compression bandaging of the knee joint was usually applied at a pressure of $25-30 \mathrm{~mm}$. $\mathrm{Hg}$, and that at this pressure the popliteal vein was compressed with a rise in resting venous pressure in the foot. This returned to normal only when the compression of the knee was reduced to $10 \mathrm{~mm}$. $\mathrm{Hg}$. They favour an inflatable splint maintained at $20 \mathrm{~mm}$. Hg. They suggest that compression bandaging should stop below the knee.

Our results agree in part with these findings. We find that pressures much in excess of $15 \mathrm{~mm}$. $\mathrm{Hg}$ retard venous flow. The increase in flow in the femoral vein achieved with whole leg compression with an inflatable splint, however, suggests that the entire limb should be encompassed to prevent stasis in the iliofemoral segment.

The increase in femoral vein flow at low external pressures is probably the result of a central reflex, as it also occurs in the control limb. The increase in venous return produced by the compression may lead to an increase in cardiac output and in limb flow. In part, the increase in the experimental limb may be due to diversion of blood from the superficial venous system to the deep (Cotton and Clark, 1965).

\section{Conclusion}

Stasis exists when blood lies stagnant in vessels at or above its normal pressure at rest. Methods at present in vogue for preventing stasis tend to substitute for it a condition where the vessels are empty and collapsed. This may in fact increase the chance of thrombosis when blood flow is restored, by causing intimal damage during the period of collapse. In the superficial venous system this may be of little consequence as thromboembolism rarely arises in these veins; however, compression or constriction of the deep venous circulation may well predispose to thrombosis.

Venous flow velocities in bandaged limbs have been measured by Stanton et al. (1949) and Makin et al. (1969). The methods used involved the injection of an indicator substance into a collapsed venous system and therefore measured the velocity of transport of the indicator rather than the velocity of blood flow. Other workers who measured limb blood flow all report an impairment at compression pressures often achieved by bandaging or by inflatable splints (Ashton, 1966; Ginsberg et al., 1967; Campion et al., 1968).

In clinical practice the use of limb bandaging and raising, either alone or in combination, for the prevention of deep vein thrombosis has had only a mixed success (Flanc, Kakkar, and Clarke, 1969).

Our investigation shows that uncontrolled application of external compression at pressure above $15 \mathrm{~mm}$. Hg impairs femoral vein flow. Of possibly greater interest is our observation that below this pressure femoral vein blood flow volume rate is increased. The changes in flow that we have observed are not large and may account for the inability of many workers to prove the efficacy of limb bandaging as a prophylactic technique.

It would seem that if external compression is to continue to be used in the treatment and prevention of deep vein thrombosis its application must be carefully controlled. The optimum pressure usually lies between 5 and $12 \mathrm{~mm}$. $\mathrm{Hg}$ but may well vary from patient to patient, depending on such factors as limb adiposity, the existence of varicose veins, the presence of lymphoedema, or previous episodes of thrombosis.

Bandaging is obviously inefficient and may well be dangerous. When applied correctly the initial tension soon slackens as the bandages work loose. Tubigrip is an improvement and, as shown by Makin et al. (1969), exerts an average pressure of 
13.8 $\mathrm{mm}$. Hg. They point out, however, that this varies with limb circumferences. Tailor-made elastic stockings are probably excellent for outpatient management, though we have not investigated as yet the pressure they exert. Inpatient management would seem to indicate the use of inflatable splints.

We wish to thank Mr. L. T. Cotton (King's College Hospital) and Professor J. M. Zarek (University of Surrey), joint heads of the biomechanics department of King's College Hospital Medical School, for their guidance and advice throughout the preparation of this paper. We also thank the sister tutors and nurses of the Training School at King's College Hospital for their kind cooperation in the leg-bandaging investigation, and Parke Davis \& Co. for supplying the inflatable splints.

The work was financed by grants from the Wates Foundation and the British Heart Foundation, to whom we express our thanks.
REFERENCES

Ashton, H. (1966). British Medical fournal, 2, 1427.
Beaconsfield, P., and Ginsburg, J. (1955). Circulation Research, 3, 478.

Campion, E. C., Hoffman, D. C., and Jepson, R. P. (1968). Australian and New Zealand fournal of Surgery, 38, 154 .

Cotton, L. T., and Clark, C. (1965). Annals of the Royal College of Surgeons of England, 36, 214

Dyde, J. A., and Bethel, A. N. (1968). British fournal of Surgery, 55, Flanc, C., Kakkar, V. V., and Clarke, M. B. (1969). Lancet, 1, 477.

Ginsberg, M., Miller, J.' M., and McElfatrick, G. C. (1967). Fournal of the American Medical Association, 200, 180.

Hodgson, D. C. (1964). Anaesthesia, 19, 96.

Husni, E. A., Ximenes, J. O. C., and Hamilton, F. G. (1968). fournal of the American Medical Association, 206, 2715.

McLachlin, A. D., McLachlin, J. A., Jory, T. A., and Rawling, E. G. (1960). Annals of Surgery, 152, 678.

McLachlin, J., and Paterson, J. G. (1951). Surgery, Gynecology and Obstetrics, 93, 1.

Makin, G. S., Mayes, F. B., and Holroyd, A. M. (1969). British fournal of Surgery, 56, 369.

Stanton, J. R., Freis, E. D., and Wilkins, R. W. (1949). Fournal of
Clinical Investigation, 28, 553. Wright, H. P., and Osborn, S. B. (1952). British Heart fournal, 14, 325.

\title{
Intravenous Isoprenaline in Treatment of Septic Shock in Man
}

\author{
J. L. WOSORNU, ${ }^{*}$ F.R.c.s. ; C. O. EASMON, $†$ F.R.c.S., F.I.c.s.
}

\begin{abstract}
Cummary: Intravenous isoprenaline was given to 10 patients in septic shock, of which occult myocardial failure was the main indication. Isoprenaline expedited recovery in cases of "benign hypotension," where kidney function paradoxically remained satisfactory at low systolic pressures, and was useful in cases of "cold hypotension" which were complicated by renal failure alone. No significant improvement occurred in cases which were complicated by both massive pulmonary oedema and acute renal failure.
\end{abstract}

\section{Introduction}

Most patients in septic shock can be managed successfully with the appropriate antibiotics in large doses, intravenous fluids, the use of oxygen, and timely surgery where applicable-in particular, drainage of closed foci of infection (Nickerson, 1962; Walters and McGowan, 1963; Frank, 1964; Lillehei et al., 1964; Baue, 1968; Blair et al., 1969). Vasodilator drugs, however, are recommended in patients who do not respond to adequate transfusion (Lancet, 1965). Examples of such drugs are hydrocortisone in massive doses, phenoxybenzamine, isoprenaline, chlorpromazine, and phentolamine.

The indications, dose, response, and side-effects of adjuvant intravenous isoprenaline in the treatment of septic shock are described. Prognosis is considered in relation to the severity of the shock syndrome. Isoprenaline was found useful in patients in whom hypotension was associated with small pulse volume and warm or cold extremities. On the other hand, with the limited resources available, it did not appreciably improve the outlook for patients who had both pulmonary oedema and acute renal failure.

\footnotetext{
* Lecturer in Surgery, Ghana Medical School, Accra, Ghana. Present address: Department of Surgery, Royal Postgraduate Medical School, Hammersmith Hospital, London W.12.

+ Professor and Head of Department of Surgery, Ghana Medical School, Accra, Ghana.
}

\section{Patients and Methods}

A prospective study was carried out on 12 patients in the Korle Bu Teaching Hospital, Accra, Ghana, who were in septic shock and in whom conventional antishock therapy had failed. Of these, 10 were women and 2 men, their ages ranging from 16 to 60 years.

All patients had severe bacterial infection associated with the following features: low blood pressure, which in five cases was unrecordable, while in the remainder the systolic was 90 $\mathrm{mm} . \mathrm{Hg}$ or lower; radial pulse rates of between 110 and 172 beats/min., which was of small volume in nine cases, imperceptible in one, but collapsing in character in two; cutaneous vasoconstriction associated with sweating (cold, clammy extremities), which was present in half the cases while extremities were warm and dry in the rest. All patients were pyrexial, with rectal temperatures ranging between 100 and $108^{\circ} \mathrm{F}$. $(37.8$ and $42.2^{\circ} \mathrm{C}$.) (though patients in septic shock may have subnormal temperatures). Oliguria (urine output below 20 $\mathrm{ml}$./hr.) was present in half the cases, including three with acute renal failure.

Thus according to the clinical classification proposed by McGowan and Walters (1966) there were six patients with "cold hypotension," one with "warm hypotension," four in whom hypotension was associated with warm extremities but small pulse volume, and one with hypotension, cold extremities, but good pulse volume.

Central venous pressure, urinary output, and electrocardiogram were monitored as well as pulse, blood pressure, temperature, and respiration. (Cardiac output, $p \mathrm{H}, \mathrm{PcO}_{2}$, and $\mathrm{Po}_{2}$ could not be measured because of lack of facilities.)

Blood pressure was measured by means of a sphygmomanometer (Kardos, 1966). Furthermore, the comment that "blood pressure is, in our experience, still best measured by the mercury sphygmomanometer at the bedside and only in special cases via an indwelling arterial cannula" (Campbell et al., $1967)$ is relevant to this clinical study. Mean arterial pressure was calculated as an approximation by adding diastolic pressure to one-third pulse pressure. 